\section{Medalha de Bronze}

Escola: Escola EB2,3/S de Macedo de Cavaleiros

Professor acompanhante:

Nuno Calisto

Equipa: Ana Rita Marcos, Daniela Fernandes, Diogo Magalhães

As 3 escolas melhor classificadas foram premiadas com o financiamento da sua participação na Semifinal do Porto das Olimpíadas de Química+, financiamento este que inclui os gastos com a deslocação (patrocínio da Câmara Municipal de Bragança) e alojamento das equipas (patrocínio do Crédito Agrícola). Este ano foi muita a emoção no momento do anúncio da escola classificada no $3 .^{\circ}$ lugar, já que se tratou de uma estreia! No que respeita à classificação escolas, ficaram classificadas em $1 .^{\circ}, 2 .^{\circ}$ e $3 .^{\circ}$ lugares, respetivamente, a Escola Secundária/3 de Mirandela, a Escola EB2,3/S de Macedo de Cavaleiros e o Colégio Torre Dona Chama.

Novamente, e mesmo em "tempos de crise económica", este evento contou com o já habitual e indispensável patrocínio monetário do Crédito Agrí- cola e com o apoio da Câmara Municipal de Bragança na deslocação à Semifinal do Porto, pelo que deixamos uma palavra especial de agradecimento a ambos os patrocinadores, o nosso Muito obrigada por continuarem a fazer possível a realização desta "festa da química" que se vive no dia das provas da Fase Regional de Bragança das $\mathrm{OQ}+$.

Joana Amaral (jamaral@ipb.pt)

Coordenadora da Fase Regional de Bragança das $\mathrm{OQ}^{+}$
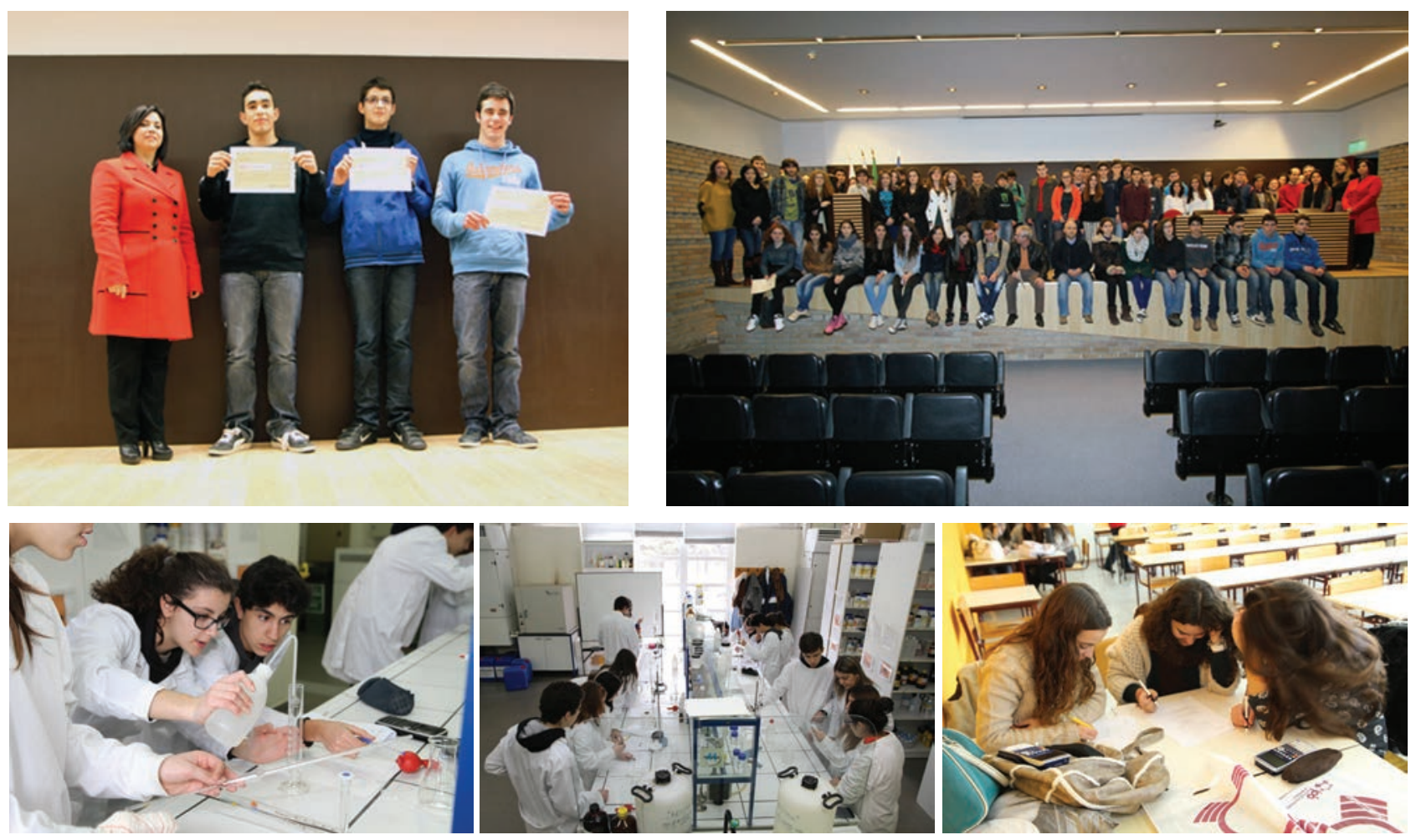

Fotografias do ambiente vivido nas provas. Em cima, à esquerda, equipa classificada em $1 .^{\circ}$ lugar

\title{
Assembleia Geral da EuCheMS em 2012
}

A Assembleia Geral da EuCheMS decorreu nos dias 11 e 12 de outubro de 2012, no Instituto de Química em Dublin, Irlanda, tendo reunido representantes das diversas Sociedades membro da EuCheMS e outras organizações associadas, representantes das Divisões, Grupos de Trabalho e do Conselho Executivo da EuCheMS e da Rede Europeia de Jovens Químicos, entre outros. Ulrich Schubert presidiu a Assembleia Geral, tendo dado início à reunião informando os parti- cipantes sobre as atualizações mais recentes relativas aos objetivos estratégicos da EuCheMS. Livia Simon Sarkadi, Nineta Majcen e Cristina Todasca complementaram a sua apresentação com atualizações sobre as atividades levadas a cabo nas áreas científicas das Divisões e Grupos de Trabalho da EuCheMS, entre outras.

A reunião contou ainda com dois painéis de discussão: "What are the European needs of member societies?" e "Combining forces for Horizon2020". As apresentações proferidas no âmbito desta reunião podem ser consultadas em http://www.euchems.eu/ about/general-assembly/2012-dublin-ireland/presentations-ga-2012.html.

(adaptado de EuCheMS newsletter, fevereiro de 2013)

Joana Amaral (bquimica@ipb.pt) www.spq.pt 